\title{
Retailing Public Goods: The Economics of Corporate Social Responsibility*
}

\author{
Timothy Besley and Maitreesh Ghatak \\ London School of Economics
}

Revised June 2007.

\begin{abstract}
This paper explores the feasibility and desirability of Corporate Social Responsibility (CSR). We identify CSR with creation of public goods or curtailment of public bads. Using a model with profitmaximizing firms, the paper shows that there is a direct parallel between CSR and traditional models of private provision of public goods. Indeed, firms that use CSR will produce public goods at exactly at the same level as predicted by the standard voluntary contribution equilibrium for public goods. We compare CSR with government provision and charitable provision, discussing when CSR by private for-profit firms could have a comparative advantage in dealing with public goods provision.
\end{abstract}

${ }^{*}$ We are grateful to Jim Andreoni, Erlend Berg, Ted Bergstrom, Jordi Blanes, Patrick Francois, Clare Leaver, Rocco Macchiavello, several seminar audiences and especially, an anonymous referee, for helpful feedback. We thank the E.S.R.C. for financial support under grant RES-000-23-0717. 
"Somebody once said that a principle isn't a principle unless it costs you money... A company which cares as much about how it makes money, as how much money it makes, will make money." Advertisement by Shell. ${ }^{1}$

\section{Introduction}

The comparative merits of particular institutions to achieve social ends is a central concern in economics. The traditional view, going back at least to Adam Smith, sees private enterprise as being the handmaiden of wealth creation. Issues arising from the existence of public goods and externalities are the preserve of government or eleemosynary institutions such as non-profits. Some, often unstated, notion of comparative institutional advantage underpins this view. Private enterprise channels greed to achieve the social end of maximizing wealth whereas government and non-profits channel benevolence to deal with other social ends.

But this neat dichotomy is frequently attacked. On one side, government and eleemosynary institutions are sometimes seen as organs of waste, corruption and incompetence, thereby questioning their ability to fulfill their designated role. A growing literature in political economy explores these issues on the side of government behavior. Perhaps as the flip side of this, there is a movement that wishes to derive a broader social role for private enterprise via corporate social responsibility (CSR). As variously constituted, this view suggests that corporations should pay attention to a broader group of stakeholders - customers, workers and communities beyond their usual obligations to shareholders.

CSR is now widely discussed in newspapers and business school curricula. There is also widespread evidence that customers care about CSR when choosing where to shop. For example MORI find that $70 \%$ of consumers are willing to pay more for a product which they perceive as ethically superior. $^{2}$ Fairtrade brands such as Cafedirect command $5 \%$ of the UK market for ground coffee. ${ }^{3}$ The Social Investment Forum reports that professionally managed "socially responsible investment" (defined as investments that con-

\footnotetext{
1 The Economist, Dec 6-12, 2003.

${ }^{2}$ See http://www.mori.com/polls/2003/mori-csr.shtml.

${ }^{3}$ Fairtrade now has $18 \%$ of the UK roast \& ground coffee market and also $4 \%$ of the total UK banana market.
} 
sider the social and environmental consequences of investments, both positive and negative) assets were roughly $12 \%$ of total assets under management in the US (Geczy, Stambaugh, and Levin, 2003). ${ }^{4}$ In spite of being a much discussed topic in the business literature and the popular press, CSR has not been, in general, located in standard price theory. ${ }^{5}$ Here, we identify CSR explicitly with the creation of public goods and curtailment of public bads jointly with the production of private goods. ${ }^{6}$ While we couch our story in terms of product market competition among firms for "ethical" and neutral consumers, it applies to labour markets (labour donation), or capital markets (ethical investment).

Economists, on the whole, have taken a skeptical view of CSR. The first line of attack concerns whether CSR is feasible in a competitive economy. For example, Baumol (1991) argues that CSR requires sacrifice of profits which is not possible when competition is intense. The second line of attack questions whether CSR is desirable. Most famous is Friedman (1970) who argues that private corporations should get on with the business of making profits while governments should deal with public goods and externalities. ${ }^{7}$

Our model allows us to investigate both the feasibility and desirability arguments. We show that CSR is consistent with profit-maximization in competitive markets. In equilibrium firms sell ethical brands and neutral brands, and consumers self-select according to their valuation of the public good. Only those who care about the cause that the firm is taking up are willing to buy the product - as long as other consumers are neutral, there is no adverse effect on those who do not care. Hence, CSR creates a Pareto improvement. We show that CSR will be at the same level as the voluntary contributions equilibrium hence always leads to a sub-optimal (excessive) level of public goods (bads).

Having established this, we look at the issue of comparative institutional advantage. In the presence of transactions costs, there is a choice between specific institutional forms to deliver social goals. We show that CSR has the greatest advantage when the public good is naturally bundled with the

\footnotetext{
${ }^{4}$ Also, there seems to be a clear upward trend: from 1999-2001 SRI assets grew by $36 \%$ as opposed to the $22 \%$ rise in all professionally managed assets. See Geczy, Stambaugh, and Levin (2003).

${ }^{5}$ Exceptions are Baron (2001), Bagnoli and Watts (2003) and Kotchen (2006).

${ }^{6}$ This contrasts with the literature which identifies corporate charitable contributions with advertizing (see, for example, Navarro (1988)).

${ }^{7}$ See also Henderson (2001).
} 
production of a private good. For example, manufacturers of sneakers can choose whether to use child labor and cosmetics manufacturers can choose whether to engage in animal testing. The government enjoys the advantage of being able to internalize externalities and to be able to impose taxes on its citizens, and spread the cost of public goods among taxpayers. However, it may not use the right social weights in making decisions and there may also be failures due to imperfect monitoring. In either case, CSR may have a comparative advantage.

Assuming an identical production technology for public goods, then without any opportunism, non-profit provision and CSR provision are essentially the same. The non-distribution constraint makes non-profits less susceptible to opportunism than CSR. CSR is advantageous if monitoring of the corporate sector is better and/or there is a natural reason to bundle public and private goods production.

There is a small existing literature on CSR related to this paper. The most relevant are Bagnoli and Watts (2003) and Kotchen (2006). Both papers, like us, view CSR as private provision of public goods. Bagnoli and Watts (2003) studies the feasibility of CSR by private firms with "warm-glow" preferences for public goods. It contrasts Bertrand and Cournot competition and shows that a positive level of public goods (below first best) can be provided in a market equilibrium. Kotchen (2006) looks at the choice of consumers between consuming an impure public good that generates private and public goods as a joint product, and consuming the private good separately and making a contribution to a pure public good. He studies what happens to aggregate provision when the impure public good is introduced as in the case of green markets. One of his main results is that when the impure public good is simply a bundled version of the private and the public good with no technological advantages (e.g., firms donating a fraction of their revenues to charity) then introducing it will not affect the equilibrium provision of the public good that will arise in a standard voluntary contributions equilibrium.

In similar vein, Arora and Gangopdhyay (1995) analyze firm competition for "green" consumers, without considering the public goods aspect of the problem. Brekke and Nyborg (2005) look at a problem where firms use CSR as a screening device to attract motivated workers. The work of Baron (2001) gets more to issues of desirability of CSR. He models strategic CSR as firms' response to private politics where lobbyists put pressure on firms to adopt more stringent environment standards. He assumes that the initial environmental quality is at the first-best level so that lobbying leads to redis- 
tribution from firms to consumers, creating a distortion. While not directly related to CSR, Gordon (2003) makes a relevant argument by observing that shareholders in widely held corporations will have an incentive to care about outcomes beyond the narrow decisions made by the firm. This will in turn influence the firm's behavior.

The paper is also related to the large literature on private provision of public goods going back to the classic contributions by Warr (1983) and Bergstrom, Blume and Varian (1986) (see Cornes and Sandler, 1996 for an extensive treatment). This examines when private action can lead to public goods provision even though there is an underlying free-rider problem. As with Bagnoli and Watts (2003) and Kotchen (2006) we show that there is a close parallel between CSR and insights from that literature.

The remainder of the paper is organized as follows. In the next section, we lay out the model and the main result which shows at what levels we would expect corporations to voluntarily contribute to public goods/bads. In section three, we discuss the sustainability of CSR when firms cannot commit. Section four then returns to the comparative institutional analysis. Section five concludes.

\section{The Model}

We develop a simple model to make the main points. It has public and private goods along with competition between firms. The competitive case is interesting since it is hardest to explain the existence of anything "waste-

ful" such as CSR. If firms enjoy some monopoly power, then they could be spending their rents in a variety of ways, of which CSR could be one example.

\subsection{The Environment}

There is a public good and two private goods, one of which is not produced and serves as the numeraire. All consumers and producers value the numeraire good and have endowments of it. The other private good needs to be produced, and its level is denoted by $x$. The public good needs to be produced as well, and its level is denoted by $g$. There are $N$ potential consumers of good $x$, each of whom receives utility $b>0$ from consuming one unit of it. To make things simple, they are distinct from those who have a technology to produce good $x$. 
One group of consumers (whom we refer to as caring) value the public good. Their valuation function is $f(g)$ which we assume to be increasing and strictly concave. The size of this group of consumers is $n \leq N$. We refer to the remainder of the population, whose size is $N-n$, as neutral - they do not care about the public good. Let preferences be quasi-linear:

$$
V^{i}(p, g)=b-p+\gamma^{i} f(g)
$$

denotes the utility of a consumer where $\gamma^{i} \in\{0,1\}$ where $\gamma^{i}=1$ if the consumer is caring.

$$
V^{n}(p, g)=b-p
$$

denotes the utility of a neutral consumer.

There is free entry. We assume there are $S>3$ potential producers who can produce a unit of the private good at $\operatorname{cost} c+\alpha \theta$ where $\theta \geq 0$ is the amount of public good that they commit to produce alongside the private good. Let $\mathcal{S}$ be the set of firms. Each producer has the capacity to serve the entire market. While the private good is homogeneous, producers can offer different levels of the public good (i.e. different $\theta$ s) in combination with the private good to serve different consumers. We assume that an individual firm can produce a single level of $\theta$ rather than being able to offer a menu of choices. Thus, $\theta$ is best thought of as representing the mission of the firm rather than a statement that applies to a single product. However, this distinction is not important unless one considers multi-product firms. ${ }^{8}$

\subsection{Market Equilibrium}

In a market equilibrium firms maximize profits and consumers maximize utility. We assume that firms move first and announce a $\left(p_{j}, \theta_{j}\right)$ pair. Consumers then decide which firm to purchase from or whether not to buy the good at all. Consumers decisions are interdependent on account of the fact that firms are producing a public good. Hence, we require that their consumption decisions form a Nash equilibrium given the prices and missions announced by firms.

\footnotetext{
${ }^{8}$ We examine later the implications of adding a "warm glow" component to the preferences of caring consumers along the lines of Andreoni (1988) so that:

$$
V^{i}(p, \theta, g)=b-p+\gamma^{i}[f(g)+v(\theta)] .
$$
}


Consider the equilibrium among consumers for fixed pricing and mission strategies by firms: $\left\{\left(p_{j}, \theta_{j}\right)\right\}_{j=1}^{S}$. To characterize consumer behavior, let $\delta_{i j}=1$ if and only consumer $i$ shops at firm $j \in \mathcal{S} \cup\{0\}$. We create a fictitious firm 0 to denote the possibility that the consumer chooses not to purchase the good, in which case $V^{i}\left(p_{0}, g\right)=\gamma^{i} f(g)$. A consumer's decision can be denoted by the vector $\delta_{i} \equiv\left(\delta_{i 0}, \delta_{i 1}, . ., \delta_{i S}\right)$.

A consumer equilibrium is a collection of shopping decisions $\left\{\delta_{i}^{*}\right\}_{i=1}^{N}$ characterized by:

$$
\begin{aligned}
\delta_{i j}^{*}\left(\left\{\left(p_{j}, \theta_{j}\right)\right\}_{j=1}^{S}\right) & =1 \text { iff } j=\arg \max _{j \in \mathcal{S} \cup\{0\}}\left\{V^{i}\left(p_{j}, \theta_{j}+\sum_{k \neq i} \sum_{s \in \mathcal{S}} \theta_{s} \delta_{k s}^{*}\right)\right\} \\
\text { for all } i & =1, \ldots, N .
\end{aligned}
$$

and 0 otherwise. Let

$$
s_{j}\left(\left\{\left(p_{s}, \theta_{s}\right)\right\}_{s=1}^{S}\right)=\sum_{i=1}^{N} \delta_{i j}^{*}\left(\left\{\left(p_{s}, \theta_{s}\right)\right\}_{s=1}^{S}\right)
$$

be the number of consumers who shop at firm $j$ in a consumer equilibrium.

A producer equilibrium is a set of prices and mission strategies by firms $\left\{\left(p_{j}^{*}, \theta_{j}^{*}\right)\right\}_{j=1}^{S}$ which maximize their profits given the shopping behavior of consumers and the strategies of other firms:

$$
\left(p_{j}^{*}, \theta_{j}^{*}\right)=\arg \max _{\left(p_{j}, \theta_{j}\right)}\left(p_{j}-c-\alpha \theta_{j}\right) s_{j}\left(\left\{\left(p_{s}^{*}, \theta_{s}^{*}\right)_{s \neq j},\left(p_{j}, \theta_{j}\right)\right\}\right) \text { for all } j \in \mathcal{S} .
$$

The following proposition characterizes the market equilibrium:

Proposition 1 The unique equilibrium is characterized by two pairs of price and public goods contributions $\left(p_{n}^{*}, \theta_{n}^{*}\right)$ and $\left(p_{c}^{*}, \theta_{c}^{*}\right)$, the first for neutral consumers and the second for caring consumers, such that:

$$
\begin{aligned}
p_{n}^{*} & =c \text { and } \theta_{n}^{*}=0 \\
p_{c}^{*} & =c+\alpha \theta_{c}^{*} \text { and } f^{\prime}\left(n \theta_{c}^{*}\right)=\alpha .
\end{aligned}
$$

The proof of this result is in the Appendix. Firms compete in a Bertrandlike fashion. They have unlimited capacity and identical cost functions and therefore earn zero profits in equilibrium. There are two kinds of firm operating in equilibrium - those catering to neutral consumers and those catering 
to caring consumers. The neutral firms are "standard" competitive firms producing a private good priced equal to marginal cost and not producing any of the public good. The caring firms contribute to the public good and charge a higher price for the private good to reflect this. Competition guarantees that the price charged by the caring firms exactly finances the cost of the public good.

In the outcome described in Proposition 1, CSR - defined here as production of the public good in market equilibrium - is produced as part and parcel of the market process. Only those who care about the cause that the firm is taking up are willing to buy the product - and as long as other consumers are neutral, there is no adverse effect on those who do not care about the cause. Hence, the CSR generates a Pareto improvement over a situation in which only neutral products are produced. There is also no issue of adjudicating by some non-market decision making whether a cause is good or bad. This is determined by whether it passes a market test.

\subsection{Implications}

There are several interesting aspects of this outcome which are worth emphasizing.

Observation 1: The level of the public good provided under CSR is the same as if the caring consumers were making private voluntary contributions to the public good and therefore the level of provision is below the first-best level.

Thus CSR is subject to the same free-riding problems as voluntary contributions to public goods. ${ }^{9}$ Indeed, in the UK, data on ethical consumerism show that although most consumers are concerned about environmental or social issues with $83 \%$ of consumers intending to act ethically on a regular basis, around $5 \%$ of consumers show consistent green and ethical purchasing behavior (Co-operative Bank, UK, 2000). Caring consumers do not internalize the positive externalities arising from their purchasing the "ethical" version of the good on other caring consumers and therefore, as in a voluntary contributions equilibrium it is under-provided. ${ }^{10}$ The first-best level

\footnotetext{
${ }^{9}$ Bagnoli and Watts (2003) also shows that there will be underprovision. However, they do not make the link to the literature on the voluntary contributions equilibrium of a private provision game.

${ }^{10}$ See, for example, Cornes and Sandler (1996).
} 
of provision of public goods is obtained by applying the standard LindahlSamuelson rule for optimal provision of public goods in the present context, namely, $n f^{\prime}\left(n \theta_{c}^{* *}\right)=\alpha$.

This observation may suggest that there is really no difference between a private charity alongside neutral production of the good. However, as we discussed above, there are many situations where there is a natural bundling of public and private goods provision, i.e., when these goods are joint products. $^{11}$

Observation 2: In the competitive CSR equilibriums caring consumers strictly prefer buying the ethical version of the good to switching to the neutral version of the good and therefore the allocation is robust to consumers' valuations of the public good being subject to private information.

Given the competitive nature of the market, consumers enjoy the full surplus arising from consumption of the private good. Prices charged by firms equal the costs of providing each type of good. Consequently, the "self-selection" constraint for neutral consumers holds since they would be strictly worse off buying the ethical version of the private good. If public goods are provided at the level characterized in Proposition $1\left(f^{\prime}\left(n \theta_{c}^{*}\right)=\alpha\right)$ then the self-selection constraint for caring consumers is also satisfied. If a caring consumer switches to a firm serving neutral consumers, the amount of public good provided will fall by $\theta_{c}^{*}$ (the per capita contribution by each caring consumer). Since he was indifferent between both varieties at the margin and has a concave utility function, this makes him strictly worse off. Thus he prefers to consume the ethical good. ${ }^{12}$ Therefore, as in standard screening models with competitive firms (e.g., Rothschild and Stiglitz, 1976) if consumers' valuations are private information we would still get the same

\footnotetext{
${ }^{11}$ This is related to an important parallel result in Kotchen (2006) who looks at pricetaking consumers and shows that, when the impure public good is a bundled version of the private good and the public good (i.e., there are technological advantages), then introducing green markets will not affect the level of provision of the public good, which will remain at the private voluntary contributions equilibrium level. The result developed here shows that, if firms compete for consumers in Bertrand fashion and prices and production decisions are endogenous, then this process leads to a market equilibrium where the level of the public good provided is the same as in a private voluntary contributions equilibrium.

${ }^{12}$ Formally, the loss of utility is of the amount $f\left(n \theta_{c}^{*}\right)-f\left(n \theta_{c}^{*}-\theta_{c}^{*}\right)$ while the saving in terms of money is $\alpha \theta_{c}^{*}$ due to the lower price of the neutral version of the good. As the utility function is strictly concave, $\frac{f\left(n \theta_{c}^{*}\right)-f\left(n \theta_{c}^{*}-\theta_{c}^{*}\right)}{\theta_{c}^{*}}>\alpha=f^{\prime}\left(n \theta_{c}^{*}\right)$.
} 
outcome.

Observation 3: Raising CSR standards among firms who supply caring consumers can create a Pareto improvement but cannot, in general, generate the first-best outcome.

The highest level of $\theta$ that can be sustained makes caring consumer indifferent between the ethical and the neutral version of the good. This will be $\bar{\theta}_{c}$ as defined by $f\left(n \bar{\theta}_{c}\right)-f\left((n-1) \bar{\theta}_{c}\right)-\alpha \bar{\theta}_{c}=0$. Firms will earn zero profits if $p_{c}=c+\alpha \bar{\theta}_{c}$ and $p_{n}=c$. It is easy to see that $\bar{\theta}_{c}>\theta_{c}^{*}$. If there were some means of raising $\theta$ to $\bar{\theta}_{c}$, then this would generate a Pareto improvement over the situation described in Proposition 1 . In general $\bar{\theta}_{c}$ will, however, lie below the first outcome, $\theta_{c}^{* *}$, where $n f^{\prime}\left(n \theta_{c}^{* *}\right)=\alpha$. For utility functions that satisfy $-\frac{g f^{\prime \prime}(g)}{f^{\prime}(g)} \leq 1$, i.e., the marginal utility does not diminish very fast (examples include standard utility functions such as the Cobb-Douglas and the logarithmic utility function) $\bar{\theta}_{c}<\theta_{c}^{* *}{ }^{13}$ Only if the marginal utility diminishes very fast would the first-best level be relatively low (even though it is always higher than the level under a competitive CSR equilibrium). Then the first best may be consistent with CSR. ${ }^{14}$

Even though there is a high CSR standard that makes everyone better off, it cannot be implemented in a standard market equilibrium. Firms will have an incentive to undercut this level - offering caring consumers a lower price and lower contribution to the public good. This will attract the caring consumers since $f^{\prime}\left(n \bar{\theta}_{c}\right)<\alpha=\frac{f\left(n \bar{\theta}_{c}\right)-f\left((n-1) \bar{\theta}_{c}\right)}{\bar{\theta}_{c}}$ (by the concavity of the utility function). This illustrates one cost of competition in delivering ethical outcomes along the lines argued by Baumol (1991).

Observation 4: An exogenous increase in the provision of the public good

\footnotetext{
${ }^{13}$ Consider any given level of $\theta>0$. We will show that $\frac{f(n \theta)-f((n-1) \theta)}{\theta}<n f^{\prime}(n \theta)$. This would impliy that $\bar{\theta}_{c}<\theta_{c}^{* *}$. The relevant inequality can be rewritten as $f(n \theta)-$ $f((n-1) \theta)<n \theta f^{\prime}(n \theta)$. By concavity $f(n \theta)-f((n-1) \theta)<\theta f^{\prime}((n-1) \theta)$. Now so long as $-\frac{g f^{\prime \prime}(g)}{f^{\prime}(g)} \leq 1$, the function $g f^{\prime}(g)$ is non-decreasing, and so $n \theta f^{\prime}(n \theta) \geq(n-$ 1) $\theta f^{\prime}((n-1) \theta) \geq \theta f^{\prime}((n-1) \theta)$ for $n \geq 2$.

${ }^{14}$ Consider, for example, the utility function $f(g)=a g-b g^{2}$ with $a>\alpha, b>0$ and $g \leq \frac{a}{2 b}$. Then its straightforward to check that $-\frac{g f^{\prime \prime}(g)}{f^{\prime}(g)}$ would exceed 1 for high values of $g\left(g \geq \frac{a}{4 b}\right)$. In this case, it is possible for the first-best to be attained by raising CSR standards if $a>\alpha n\left(1+\left(1-\frac{1}{n}\right)^{2}\right)$ which will be satisfied for low values $n$.
} 
(e.g., by the government) will crowd-out competitive provision under CSR. CSR will not occur if the surplus maximizing level of the public good is provided.

This parallels the standard result for charitable provision of public goods. To see this, observe that if $\bar{G}$ is the exogenously given level of the public good by the government, then the equilibrium provision under CSR will solve $f^{\prime}\left(n \theta_{c}^{*}+\bar{G}\right)=\alpha$. An increase in $\bar{G}$ will reduce provision via CSR dollar-for-dollar.

The surplus maximizing level of the public good is given by:

$$
G^{*}=\arg \max \{n f(G)-\alpha G\}
$$

which yields:

$$
n f^{\prime}\left(G^{*}\right)=\alpha .
$$

It is clear that $\theta_{c}^{*}=0$ if $G^{*}$ is chosen by government. This observation illustrates the classical dichotomy between the role of private firms and government which lies behind the critique of CSR by Friedman (1970). As we shall investigate further below, the argument for CSR must rest on some imperfection in the workings of government.

Observation 5: Adding warm-glow utility $v(\theta)$ to the caring consumers' preferences will leave the results essentially unchanged.

In this case the competitive equilibrium with CSR will solve $v^{\prime}\left(\theta_{c}^{*}\right)+$ $f^{\prime}\left(n \theta_{c}^{*}\right)=\alpha .^{15}$

\subsection{Sustainability}

The above analysis assumes that firms can make credible promises to provide public goods. However, profit maximizing firms have an incentive to offer to do so and then renege on this promise. Thus, the result in Proposition 1 holds only if either there are binding contracts over $\theta$ or sufficient reputational/legal penalties ex post for cheating customers. Casual observation suggests that firms spend a great deal of effort on advertising to create ethical images in an attempt to convince customers of their social credentials.

In this section, we extend the model to show what happens when reputations are used to enforce good behavior using the framework of Klein and

\footnotetext{
${ }^{15}$ The extension of Propostion 1 in this case is in the Appendix.
} 
Leffler (1981) and Shapiro (1983). A firm can enter the market offering a high price and a high level of socially responsible behavior. There is an infinite horizon and, in each period, the firm can either provide the promised contribution to the public good $\theta$ or cheat and set $\theta=0$. If it is caught cheating, we assume that the firm is punished forever and makes zero profits (it can produce for the non-caring consumers for which no reputation is needed). We posit a monitoring technology which catches a cheating firm with probability $q$ if it sets $\theta=0$ and that firms discount the future with the discount factor $\beta<1$. We will look for that stationary strategy which supports the highest level of CSR along the equilibrium path.

To characterize this, let $p_{c}$ be the price of a CSR product with contribution $\theta_{c}$. Then if the firm does not cheat, its value function is:

$$
\Pi=\left(p_{c}-c-\alpha \theta_{c}\right)+\beta \Pi
$$

or

$$
\Pi=\frac{\left(p_{c}-c-\alpha \theta_{c}\right)}{1-\beta} .
$$

Now consider a firm that cheats for one period (applying the standard oneperiod deviation principle). In this case it gets a higher profit in the short run, but loses its reputation with probability $q$. The value function for this case is:

$$
\hat{\Pi}=p_{c}-c+(1-q) \beta \Pi .
$$

Honesty is sustainable if $\Pi \geq \hat{\Pi}$ or

$$
p_{c} \geq c+\phi(q, \beta) \alpha \theta_{c}
$$

where: $\phi(q, \beta)=\left(\frac{1-\beta+q \beta}{q \beta}\right)>1$. This incentive constraint must be satisfied for a CSR strategy to be credible. Prices for firms that engage in CSR now exceed costs, so that firms have to earn a rent in order to promise CSR credibly. The one period profit of a CSR firm is:

$$
(\phi(q, \beta)-1) \alpha \theta_{c} \text {. }
$$

The firms rent is increasing in $\theta$ which provides an underpinning for the often heard claim that the pursuit of profit and the social good are not contradictory goals. In equilibrium, firms that promise more contributions to worthwhile causes must earn a rent for this to be incentive compatible. 
As we would expect, the size of the rent is decreasing in $\beta$ and $q$. The more patient the firms are, and the more effective the monitoring technology, the lower will have to be the rents to induce incentive-compatibility.

We now characterize the equilibrium allocation in a competitive market where in the presence of the possibility of opportunism by firms regarding their promised level of delivery of public goods, the reputational mechanism described above is used. The following result parallels Proposition 1 for this case.

Proposition 2 The optimal sustainable level of CSR when consumers cannot perfectly monitor whether the firm delivers the promised level of the public good is given by:

$$
f^{\prime}\left(n \hat{\theta}_{c}\right)=\phi(q, \beta) \alpha
$$

which is lower than the case of perfect monitoring, and the corresponding equilibrium price is $\hat{p}_{c}=c+\phi(q, \beta) \alpha \hat{\theta}_{c}$.

The proof of this result is in the Appendix. The incentive-compatibility constraint for CSR raises the marginal cost of providing the public good and as a result, the equilibrium level will be lower than in the case where firms have no scope for opportunism. If $\beta$ and $q$ are high then $\phi(q, \beta)$ is close to 1 and so the level of the public good will approach the level that could be attained if there were contracting over $\theta$. However, for low $\beta$ and low $q$, this will not be the case and firms will not be able to credibly offer CSR. In the limit as either $\beta$ or $q$ goes to zero, no CSR is sustainable.

This result allows us to reflect on Baumol (1991)'s pessimistic conclusion about the ability of the market to uphold ethical behavior by firms. With imperfect credibility, rents may indeed be necessary for CSR if they are needed to enforce a reputation.

The analysis also makes clear why firms might be willing to invest in technologies that raise $q$. This has interesting implications for corporate governance. Firms may be willing to invite NGO's or other third parties to inspect the activities of the corporation to see whether they comply with their CSR claims. This could even include board level monitoring of the corporation's activities. An alternative accountability mechanism is receiving certification from organizations such as the Fairtrade Foundation. ${ }^{16}$

\footnotetext{
${ }^{16}$ Fairtrade products sell at a slightly higher price than non-Fairtrade conterparts and food manufacturers pay a fee to Fairtrade for the use of their mark on a product's packaging.
} 
If there is free entry and competition, even though firms that adopt CSR earn rents ex post they must earn zero expected profits ex ante. Following Shapiro (1983) this can be rationalized if firms make some losses when they enter that will offset the rents earned subsequently. For example, this can take the form an introductory price offer that is below marginal cost, or expenditure on advertising. To close the model, we suppose that firms have to spend an initial amount $F$ on advertising when they decide to produce the ethical version of the good. Otherwise the consumers will infer they are not supplying the promised level of the public good. In equilibrium, $F$ must equal $\Pi$ for the ex ante zero profit condition to hold. Therefore, our point on the willingness of firms to invest in $q$ holds only to the extent there are some entry barriers (e.g., due to patents, brand name) so that ex ante profits are not driven down to zero.

\section{Comparing Institutions}

We now look in greater detail at the desirability of CSR by comparing it to two alternative institutional arrangements for provision of public goods

- government and non-profits. Our aim is to embed CSR in a theory of comparative institutional advantage.

\subsection{Government versus CSR}

We have already seen that the case for CSR must rest on the inability of government to achieve the first best allocation. For cases where CSR is a donation to a charitable activity such as funding an exhibition or sponsoring the opera house, this seems like a powerful argument except in so far as firms get benefits from advertising. The more interesting case is where the CSR activity is intrinsically bundled with the firm's production process. In this case, government provision is not an option and blunter instruments such as regulation seem more plausible. Even so, with sufficient information, a benevolent and omniscient government can clearly generate the first best. We now consider some departures from first-best government.

\subsubsection{Uniform Regulations}

Suppose that the government decides to use a uniform standard that affects all firms. We have the following result on the welfare impact of introducing 
a small uniform regulatory intervention, i.e. the introduction of a regulation around the zero regulation point:

Proposition 3 Suppose that $b>c$, then a small uniform regulation on the level of $\theta$ has two effects (i) it leaves the total contribution to the public good unchanged (ii) it would lead to redistribution of contributions from caring to neutral consumers.

Profit maximizing firms that serve caring consumers now reduce the value of $\theta_{c}^{*}$ to achieve a one-for-one crowd-out in contributions. The effect of these reduced contributions made by caring consumers is lower the price of the ethical good. There is now an increase in the price paid by neutral consumers who (since $b>c$ ) now finance some of the public good even though the total level produced remains the same. Total surplus is the same. However, the regulation redistributes from neutral to ethical consumers.

For larger levels of regulation, there is an impact on the level of public goods provided in equilibrium. This is because, for a large enough regulation, there will eventually be an increase in total contributions to the public good. The following result describes what happens in this situation when the regulation is picked to maximize total surplus:

Proposition 4 Let $\hat{\theta}$ solve:

$$
n f^{\prime}(N \hat{\theta})=\alpha
$$

If $b \geq c+\alpha \hat{\theta}$, the first-best level of public goods provision can be achieved by a uniform regulation which stipulates that all firms must provide $\hat{\theta}$ units of the public good for every unit of the private good provided.

The condition $b \geq c+\alpha \hat{\theta}$ says that the neutral consumers are still willing to buy the good at the higher price needed to finance the first best level of public goods provision when public goods provision is mandatory. It is then as if the government were financing contributions to the public good using a uniform head tax (as in the next subsection). Otherwise, the first best is not possible through a uniform regulation which will result in neutral consumers not buying the good at all.

This analysis is related to Baron (2001). He observes that private politics, i.e. lobbying of firms, cannot distort the allocation in a competitive CSR 
equilibrium. If this is targeted only to firms selling the ethical version of the good, then efficiency will increase as only the highest valuation consumers contribute in such an equilibrium and there is underprovision of the public good. However, like a uniform regulation, private politics can have a negative effect if it also applies to firms selling the neutral version of the good. Indeed, at the extreme it is possible to stop the production of the neutral version by raising the cost of the private good, $c$.

\subsubsection{Government Failure}

In assessing the case for CSR, there are three possible sources of government failure to consider. The first reflects the possibility that the marginal cost of providing the public good is higher for government $\left(\alpha_{g}>\alpha\right)$. This could be due to the firm knowing better than the state how best to modify production to achieve social goals. It could also be due to some intrinsic jointness between the private and public good production processes. The second reflects the distributional preferences of the government, in particular, the weight that it places on the welfare of caring vs. neutral consumers. The third refers to consequences of government opportunism.

To study these latter two cases, we focus on the case where government can directly provide the public good at the same marginal cost as private firms, $\alpha$, and picks the policy preferred by a majority of citizens. We assume that the government finances its interventions using a uniform head tax. The outcome will now depend on whether the caring or the neutral consumers are a larger group. Let $\pi \equiv \frac{n}{N}$ denote the fraction of citizens who are caring.

If the neutral consumers are in a majority $\left(\pi<\frac{1}{2}\right)$, then $G_{g}^{*}=0$. In this case, CSR generates a Pareto improvement even if government provision is possible since the government does not represent the interests of caring consumers.

If the caring consumers are in a majority $\left(\pi \geq \frac{1}{2}\right)$, they set a level of public goods such that:

$$
N f^{\prime}\left(G_{g}^{*}\right)=\alpha
$$

which exceeds the surplus maximizing level. This excessive provision arises because the neutral consumers are being forced to pay some of the taxes which the caring consumers do not internalize. In contrast CSR does not pose a burden on the neutral consumers. It is like having a public good financed by a benefit tax. Total surplus with government provision can be higher or lower than with provision under CSR. 
We state this argument in:

Proposition 5 If $\pi<1 / 2$, CSR generates a Pareto improvement. If $\pi \geq$ $1 / 2$, government provision will lead to overprovision with respect to the firstbest level but will generate a higher surplus than CSR so long as $N$ is higher than some critical value $\underline{N}>1$.

The proof is in the appendix. This result is driven by the fact that the extent of loss due to free-riding under CSR is higher, the higher is $n$, i.e., given $\pi$, the higher is $N$.

We now turn to the possibility of government opportunism. As with CSR, we suppose that government officials can consume tax revenues raised for producing public goods. This is deterred by paying an efficiency wage coupled with a threat of not being re-elected if caught "cheating". The analysis is similar to the agency model of elections introduced in Barro (1973). ${ }^{17}$

Suppose that government is run by infinitely-lived self-interested politicians (these could be thought of as parties). These must be re-elected each period and have tax raising powers. Politicians are paid a wage $w$ which is financed out of taxation. These politicians pick a level of public goods to please the group of citizens who form a majority. We will focus on the case where $\pi>1 / 2$, so that this is the caring group. The politician can cheat and consume the whole tax revenue as perks in which case he is detected with $q_{g}$. We suppose that if he is caught cheating then he is removed from office and earns an outside reward of zero thereafter.

Along the equilibrium path, the politician is honest. The value of an honest political life is $w /(1-\beta)$ while a cheater (who steals the entire public goods budget) earns $w+\alpha G+\left(1-q_{g}\right) \frac{\beta}{1-\beta} w$. The incentive constraint for honest government is therefore:

$$
w \geq \frac{1-\beta}{\beta q_{g}} \alpha G .
$$

This efficiency wage is increasing in $G$. The total cost of providing public goods $G$ is $w+\alpha G=\phi\left(q_{g}, \beta\right) \alpha G$ where $\phi(\cdot, \cdot) \geq 1$ and is defined as in section 2.4 above.

\footnotetext{
${ }^{17}$ See Persson and Tabellini (2000, Chapter 4) and Besley (2006, Chapter 3) for surveys of such models.
} 
The level of public goods that maximize a representative caring citizen's utility is:

$$
\max _{G}\left\{f(G)-\frac{\phi\left(q_{g}, \beta\right) \alpha G}{N}\right\}
$$

which yields:

$$
f^{\prime}\left(G_{g}^{*}\right)=\frac{\phi\left(q_{g}, \beta\right) \alpha}{N} .
$$

The possibility of government opportunism increases the marginal cost of public provision.

If $\phi\left(q_{g}, \beta\right)$ is small ( $\beta$ and $q_{g}$ high) then overprovision relative to the first best is likely for the same reasons as in Proposition 5 (when $\pi \geq \frac{1}{2}$ ): caring citizens do not internalize the cost of the public good that is borne by neutral citizens. On the other hand, if $q_{g}$ is small, then there will be underprovision. Let the value of $q_{g}$ that satisfies $\frac{1}{n}=\frac{\phi\left(q_{g}, \beta\right)}{N}$ be denoted by $\bar{q}_{g}$ and the value of $q_{g}$ that satisfies $\frac{\phi\left(q_{g}, \beta\right)}{N}=\phi(q, \beta)$ be denoted by $\underline{q}_{g}$. If $q_{g}>\bar{q}_{g}$ government provision subject to opportunism yields overprovision compared to the first-best and if $q_{g}<\underline{q}_{g}$ there is underprovision compared to CSR.

We summarize this as:

Proposition 6 Suppose that government and corporations are opportunistic. If $\pi<1 / 2$, then reputation-enforced CSR generates a Pareto improvement. However, if $\pi \geq 1 / 2$ then: (i) if monitoring of government is sufficiently good $\left(q_{g}>\bar{q}_{g}\right)$ then government provision will lead to overprovision compared to the first-best but will generate a higher surplus than CSR unless $N$ is small; (ii) if monitoring of government is at some intermediate level good $\left(\underline{q}_{g} \leq q_{g} \leq \bar{q}_{g}\right)$ then government provision dominates CSR; (iii) if monitoring of government is poor $\left(\underline{q}_{g}>q_{g}\right)$ then CSR dominates government provision.

A key parameter in the analysis is $q_{g}$ which could be thought of as a measure of transparency in government - the likelihood that a government is caught cheating. For some issues such a foreign aid, transparency in foreign policy might be low. This may, for example, underpin the apparent consumer preferences to use high prices for packaged coffee to support poor farmers in developing countries rather than relying on the state to do so out of taxation. However, for other issues such as building/maintaining bridges and highways, it is doubtful that CSR has much of an advantage. 
These arguments allow us to assess the force of the criticism of CSR in Friedman (1970). The government's power to tax gives it an intrinsic advantage over CSR. However, governments may fail to respond to the wishes of minorities that have strong preferences. The use of CSR can then be useful supplement to government intervention. CSR can also be important if the government's delivery on some tasks is more difficult than monitoring corporations.

\subsection{Non-profits versus CSR}

We now consider whether CSR could have an advantage over non-profit organizations, i.e. organizations which cannot distribute profits to individuals who exercise control over the firm such as officers, directors, or members (Hansmann, 1980).

We have already observed that our model predicts a level of charitable giving that parallels what would be provided through voluntary donations. To see this more clearly, suppose that the caring consumers each pick a donation $\sigma_{i}>0$ and that the donations are spent on providing the public good. Suppose that $\alpha_{n p}$ is the unit price of provision by a non-profit which operates in this way. Then, in a Nash equilibrium of the voluntary provision game:

$$
f^{\prime}\left(\sum_{i=1}^{n} \sigma_{i}\right)=\alpha_{n p} .
$$

There are many patterns of individual contributions consistent with Nash equilibrium. Here, we focus on the symmetric case where all caring individuals pay $1 / n$ of the aggregate contribution.

At face value, this analysis suggests that non-profits and CSR are equivalent except when there are reasons to believe that $\alpha \neq \alpha_{n p} \cdot{ }^{18}$ This observation is itself striking since CSR is performed by profit maximizing firms and our model of charitable donations by a non-profit firm that distributes all of its proceeds to the good cause. The equivalence result is driven in the main by the fact that there is competition in the market which means that profit maximizing firms leave all the surplus from public good provision with the caring consumer. Indeed, in this framework, it would not matter that we had competing profit maximizing charities that take donations and

\footnotetext{
${ }^{18}$ This is related to the discussion in Kotchen (2006) about choice of different technologies for the public good.
} 
supply public goods. This equivalence, as we shall see shortly, rests crucially on there being no problems of opportunism. Authors, such as Glaeser and Shleifer (2001) have rightly focused on the comparative opportunities for opportunism between for-profit and not-for-profit providers. We will return to this in our framework below.

Even in this baseline case, there may good reasons for thinking that $\alpha$ and $\alpha_{n p}$ diverge. Throughout we have emphasized the possibility of natural complementarities between some good/bad causes and private goods production. It may be very costly for a non-profit specializing in child labor advocacy to reduce child labor. But it is relatively simple for Nike to do so. Thus, the same level of the public good is cheaper in the CSR solution. Thus one reason for preferring CSR is that $\alpha_{n p}>\alpha{ }^{19}$

Once we consider sustainability issues, then there is a need to understand the credibility of non-profit donations to good causes credible. If the notfor-profit form makes it impossible for the firm to cheat by extracting rents, then this would generate a considerable advantage compared to CSR. To model opportunism by non-profit managers suppose that the latter are paid a wage of $w$. Following Glaeser and Shleifer (2001), we suppose that the non-distribution constraint implies that a non-profit manager can enjoy only a fraction $\gamma(<1)$ of any funds that he diverts to private consumption. As with our analysis of government, we suppose that he is paid a wage which deters such activities in equilibrium. If the non-profit manager "cheats" and spends donations on private perks then we suppose that he is detected with probability $q_{n p}$ and is subsequently fired. The payoff from being honest is therefore $\frac{w}{1-\beta}$. However, if the non-profit manager decides to cheat and extract the entire budget of the non-profit in the form of rents, then her payoff from a single period of cheating is $w+\gamma \alpha_{n p} G+\left(1-q_{n p}\right) \beta \frac{w}{1-\beta}$. Comparing these two expressions, the incentive constraint for the non-profit manager to remain honest is:

$$
w \geq \frac{1-\beta}{\beta q_{n p}} \gamma \alpha_{n p} G .
$$

We assume that the wage is chosen so that this holds with equality. The

\footnotetext{
${ }^{19}$ We are implicitly assuming that the non-profit does not have access to the private goods production technology. Otherwise the non-profit can provide the bundled privatepublic good.
} 
cost of providing a public good level $G$ is now

$$
w+\alpha_{n p} G=\frac{\gamma(1-\beta)+\beta q_{n}}{\beta q_{n}} \alpha_{n p} G=\left\{1+\gamma\left(\phi\left(q_{n p}, \beta\right)-1\right)\right\} \alpha_{n p} G .
$$

By increasing the cost of opportunism $(\gamma<1)$, the non-distribution constraint reduces the effective cost of providing public goods. ${ }^{20}$ This creates an advantage for a non-profit compared to CSR.

Now consider the decision by caring citizens to donate to an imperfect non-profit. The benefit to the donor is $f(G)$. The level of provision in a Nash equilibrium will be:

$$
f^{\prime}\left(G_{n}^{*}\right)=\left[1+\gamma\left(\phi\left(q_{n p}, \beta\right)-1\right)\right] \alpha_{n p}
$$

Define $\bar{q}_{n p}$ from $1+\gamma\left(\phi\left(q_{n p}, \beta\right)-1\right)=\phi(q, \beta)$. We know that $\bar{q}_{n p}<q$ for all $\gamma<1$.

If $\gamma=1$ (the rent extraction from a non-profit is very efficient) and $\alpha=\alpha_{n p}$, then the outcome under a non-profit is identical to what happens under CSR with opportunism. Otherwise, for the same level of transparency $\left(q_{n p}=q\right)$ and costs $\left(\alpha=\alpha_{n p}\right)$ non-profits deliver a higher level of the public good than CSR. This is because the non-distribution constraint makes rent extraction costly. In the limiting case where $\gamma=0$ opportunism is not an issue at all for a non-profit.

This analysis shows that the non-distribution constraint makes the problem of opportunism less severe in non-profits relative to private for-profit firms. Accordingly, we would see CSR either because the monitoring technology for private for-profit firms is superior to that of non-profits $\left(q_{n}<\bar{q}_{n}\right)$ which is plausible in some cases, or because some issues are naturally bundled with private goods provision making it likely that for-profit firms will have a cost advantage $\left(\alpha_{n p}>\alpha\right)$ in dealing with the issue. A good example of the latter is the fight against child-labor in the developing world. The instruments that non-profits have are rather blunt compared to those manufacturers have at that their disposal. Many environmental issues may

${ }^{20}$ Formally, $\gamma<1$ implies that:

$$
1+\gamma\left(\phi\left(q_{n p}, \beta\right)-1\right)<\phi\left(q_{n p}, \beta\right) .
$$


also fall into this category. But it is hard to believe that CSR is the optimal vehicle for sponsoring the arts or culture from the perspective of our model. ${ }^{21}$

\section{Discussion}

While we have developed the analysis in terms of the product market, the basic idea also applies to labor markets (labor donation), or capital markets (ethical investment). To see this, suppose that are all consumers neutral and have valuation $b$ for a private good. Assume it takes one unit of a labor input to produce one unit of output by competitive firms. The disutility of labor is $c$ and the wage rate is $w$. Assume that some workers care about the public good. Their utility function is $w-c+\gamma^{i} f(g)$ whereas for neutral workers, utility is $w-c$. As above, firms can commit to contribute to a public good jointly with the production of the private good (e.g. through using an environmentally friendly technology). The cost of this $\alpha \theta$ where $\theta \geq 0$ is the quantity of public good produced. In this case, caring workers would be willing to take a cut in the wages if the firm contributes to the public good.

We have focused mostly on public goods rather than bads. However, the main ideas carry to the case of curtailing public bads, However, two additional features arise. First, as we have already observed, private contributions to reduce public bads may not be very effective. NGO's may use resources to lobby or curtail the bad activities, but may not have a technology to directly reduce the quantity of a public bad. However, this is not the case for many instances of CSR where the corporation may itself be the perpetrator of the bad.

Our discussion of opportunism in all organizational forms has focused on incentive based solutions. However, in the case of a non-profit is clear that the opportunism problem would be solved by selection rather than incentives - in particular appointing caring citizens to run organizations with social goals. A caring citizen in a non-profit or CSR firm would implement the highest possible CSR standard that we discussed in Proposition 6. Institutions could have a comparative advantage in good causes if they are able to attract individuals who are committed to the cause. This could, of course, also be a strategy for a CSR firm wishing to make a credible commitment to $\theta>0$. Indeed, it is striking that some for-profit firms, such as the Body

\footnotetext{
${ }^{21}$ Thus, we concur with the view expressed in Navarro (1988) which sees such activities as essentially a form of advertizing.
} 
Shop, build their reputation for CSR on the back of their socially minded entrepreneurs. More generally, there are governance solutions to opportunism which might also work, such as appointing well-meaning individuals to the board in a non-executive capacity or inviting external auditors such as NGOs. Such activities are potentially part of a profit maximizing strategy - a firm that can commit to a higher level of $\theta$ than any other firm (less than or equal to $\theta_{c}^{*}$ ) will earn a rent from doing so.

This discussion of regulation above shows that there are two main differences between most forms of observed regulation and CSR. First, CSR is voluntary. Second, as we noted earlier, most regulation concerning curtailment of a public bad applies to all businesses, even those who serve customers who do not care about the cause. Thus, regulations lead to redistributions across citizens in a similar fashion to what happens with tax finance of a public good without benefit taxation. The monitoring of regulation is now shifted to the government rather than customers. Hence, the issue of opportunism depends on having an effective enforcement regime. In so far as government needs incentives to enforce regulations, we need also to take into account the possibility that the government will collude with firms. Whether regulation is better than CSR will then come down to whether monitoring by customers of the firm at a lower level of $\theta$ or monitoring through the political process at a higher level is better.

\section{Concluding Comments}

This paper has put forward a simple model to assess whether CSR is feasible and desirable. In line with many real world examples, we have modeled CSR as a response to consumers preferences over public goods/bads and hence part of a profit-maximizing strategy by firms whose businesses have external effects. We have depicted CSR as sustaining a level of public goods provision by for-profit firms operating in a competitive market.

We have shown, in line with some critics, that CSR is no panacea for standard problems of private provision of public goods, such as free-riding. Indeed, the level achieved under CSR is exactly the same as the private voluntary contributions outcome. Thus, at a basic level, Friedman (1970) is correct that perfect government trumps the case for CSR and then firms should ignore the external effects that they create.

The analysis also studies why the possibility of cheating on CSR promises 
can be overcome when future rents are at stake. Our model is consistent with finding that firms caught out by environmental groups and other campaigners will earn lower profits. In our model, more responsible firms also earn higher profits, as a reputational premium to support good behaviour. ${ }^{22}$

Friedman's argument needs to be reassessed when government works imperfectly. Effective government requires monitoring and broad based social preferences. CSR could be a reflection of distortions in government preferences or poor monitoring of government. In a world of increasing interest in corporate transactions, it may not be fanciful to believe that monitoring what corporations do is easier than some aspects of government behavior. This point can be made more forcefully still relative to the non-profit sector where monitoring may be even weaker given the institutional frameworks in place in many countries.

It is no surprise, therefore, that CSR is being talked up in an era where there is relatively less faith in government than there was a few decades ago. Our analysis emphasizes that there is a niche for CSR once we drop the most straightforward dichotomy describing the responsibilities of the state and markets.

\footnotetext{
${ }^{22}$ This is assuming that there are some entry barriers so that ex ante profits are not driven down to zero.
} 


\section{References}

[1] Andreoni, James, [1989], "Giving with Impure Altruism: Applications to Charity and Ricardian Equivalence." Journal of Political Economy, 1447-58.

[2] Arora, Seema and Shubhashis Gangopadhyay [1995]: "Toward a theoretical model of voluntary overcompliance" Journal of Economic Behavior and Organization, Vol. 28 (1995) 289-309.

[3] Bagnoli, M. and S. Watts [2003]: "Selling to Socially Responsible Consumers: Competition and the Private Provision of Public Goods", Journal of Economic Management and Strategy, Vol. 12, No. 3.

[4] Baron, David [2001]: "Private Politics, Corporate Social Responsibility, and Integrated Strategy", Journal of Economic Management and Strategy, 10(1).

[5] Barro, Robert, [1973], "The Control of Politicians: An Economic Model," Public Choice, 14, 19-42.

[6] Bergstrom, T., L. Blume and H. Varian (1986) : "On the Private Provision of Public Goods", Journal of Public Economics, 29, p.25-49.

[7] Besley, Timothy [2006], Principled Agents? The Political Economy of Good Government, Oxford: Oxford University Press.

[8] Baumol, William J., (1991), Perfect Markets and Easy Virtue: Business Ethics and the Invisible Hand, Oxford: Basil Blackwell.

[9] Brekke, Kjell Arne and Karine Nyborg [2005]: "Moral Hazard and Moral Motivation: Corporate Social Responsibility as Labour Market Screening", Mimeo. The Ragner Frisch Centre for Economic Research, Oslo.

[10] Cornes, R. and T. Sandler [1996] : The Theory of Externalities, Public Goods and Club Goods, Cambridge University Press, Second Edition.

[11] Cowe, R. and S. Williams [2000]: "Who are the ethical consumers?", The Cooperative Bank, UK. http://www.co-operativebank.co.uk/ 
[12] Friedman, Milton, [1970], "The Social Responsibility of Business is to Increase its Profits," The New York Times Magazine, September 13, 1970 available at http://www.colorado.edu/studentgroups/libertarians/issues/friedmansoc-resp-business.html

[13] Geczy, C., R. Stambaugh, and D. Levin (2003): "Investing in Socially Responsible Mutual Funds", Wharton School Finance Working Paper. http://ssrn.com/abstract $=416380$

[14] Glaeser Edward and Andrei Shleifer [2001], "Not-for-Profit Entrepreneurs," Journal of Public Economics, 81(1), 99-115.

[15] Gordon, Roger H.,[2003] "Do Publicly Traded Corporations Act in the Public Interest?", Advances in Economic Analysis 83 Policy, 3(1), http://www.bepress.com/bejeap/advances/vol3/iss1/art2.

[16] Hansmann, Henry [1980]: "The Role of Nonprofit Enterprise", Yale Law Journal, 89, 835-901.

[17] Henderson, David [2001], "Misguided Virtue: False Notions of Corporate Social Responsibility," Paper presented to the New Zealand Business Round Table.

[18] Harrison, Rob [1997]: "The rise and rise of ethical consumerism", Ethical Consumer Magazine, Winter 1997 (http://www.ethicalconsumer.org/philosophy/riserise.htm)

[19] Klein, Benjamin and Keith B. Leffler, [1981], "The Role of Market Forces in Assuring Contractual Performance", Journal of Political Economy,

[20] Kotchen, Matthew, [2006], "Green Markets and Private Provision of Public Goods." Journal of Political Economy, vol. 114, no. 4, 816-834.

[21] Navarro, Peter, [1988], "Why do Corporations Give to Charity," The Journal of Business, 61(1), 65-93.

[22] Persson, Torsten and Guido Tabellini, [2000], Political Economics: Explaining Economic Policy, Cambridge, MIT Press. 
[23] Rothschild, Michael, and Joseph Stiglitz [1976]: "Equilibrium in Competitive Insurance Markets:An Essay on the Economics of Imperfect Information", Quarterly Journal of Economics, vol. 90, no. 4, 629-649.

[24] Shapiro, Carl, [1983], "Premium for High Quality Products as Returns to Reputations," Quarterly Journal of Economics, 98 (4), 659-679.

[25] Warr, P. G. (1983) : "The Private Provision of a Public Good is Independent of the Distribution of Income", Economics Letters, 13, p.207-211.

[26] The Cooperative Bank, UK [2005]: The Ethical Consumerism Report. http://www.co-operativebank.co.uk/ 


\section{Proofs}

Proof of Proposition 1: The following three steps help simplify the characterization of the equilibrium:

First, firms set prices to make zero profits, given $\theta$ given the standard property of Bertrand competition where firms have unlimited capacity and identical cost functions.

Second, $\theta_{n}^{*}=0$. Suppose that this were not the case and that of the $\left(p_{s}, \theta_{s}\right)$ pairs offered by firms, $\underline{\theta} \equiv \min _{s \in \mathcal{S}} \theta_{s}>0$. Since neutral consumers do not value the public good at all, another firm can offer a slightly lower $\theta$ and a slightly lower price and thereby attract all the neutral consumers.

Third, all caring consumers will be offered the same package $\left(p_{c}^{*}, \theta_{c}^{*}\right)$. Suppose not. Then there must exist at least one pair of consumers, say $i=1$ and 2, who choose different packages $\left(p_{c}^{1}, \theta_{c}^{1}\right)$ and $\left(p_{c}^{2}, \theta_{c}^{2}\right)$ where $p_{c}^{1} \neq p_{c}^{2}$ and/or $\theta_{c}^{1} \neq \theta_{c}^{2}$. By the first argument, firms must be earning zero profits, i.e., $p_{c}^{1}=c+\alpha \theta_{c}^{1}$ and $p_{c}^{2}=c+\alpha \theta_{c}^{2}$. Then the only way the packages can differ is if $\theta_{c}^{1} \neq \theta_{c}^{2}$. Now observe that the two consumers buying these two packages must be receiving the same payoffs, because otherwise the firm whose package offers a higher utility will attract both consumers. Let $\hat{G}$ be the level of the public good being provided by other firms serving consumers excluding 1 and 2. Then, using the zero-profit condition, this implies:

$$
b-\left(c+\alpha \theta_{c}^{1}\right)+f\left(\theta_{c}^{1}+\theta_{c}^{2}+\hat{G}\right)=b-\left(c+\alpha \theta_{c}^{2}\right)+f\left(\theta_{c}^{2}+\theta_{c}^{1}+\hat{G}\right) .
$$

But this condition reduces to $\theta_{c}^{1}=\theta_{c}^{2}$ which contradicts our assumption that the packages offered to consumers 1 and 2 are different. Notice that the property that drives this result is the pure public good nature of the public good under consideration, namely, the utility one derives depends on total provision, and not how much an individual personally contributes.

It remains to characterize the level of public goods provision among the CSR firms. Suppose that there is a symmetric level of contributions $\hat{\theta}$ such that

$$
f^{\prime}(\hat{\theta} n) \neq \alpha
$$

and a corresponding price $p$. Suppose that a firm enters and offers a package $\left(p^{\prime}, \hat{\theta}^{\prime}\right)$ with $p^{\prime}=p+\triangle p$ and $\hat{\theta}^{\prime}=\hat{\theta}+\triangle \hat{\theta}$ where $\triangle p=f^{\prime}(n \hat{\theta}) \triangle \hat{\theta}$. As $f^{\prime}()>0,. \triangle \hat{\theta}$ and $\triangle p$ can be positive or negative but have the same sign. We show that there exists a package of this form which will make each caring 
consumer strictly better off. The payoff of a caring consumer who accepts this package is $b-p^{\prime}+f\left(\hat{\theta}^{\prime}+(n-1) \hat{\theta}\right)$. The change in profits for the entering firm (compared to offering $\hat{\theta}$ ) is:

$$
\triangle p-\alpha \triangle \hat{\theta}=\left(f^{\prime}(n \hat{\theta})-\alpha\right) \triangle \hat{\theta}
$$

This is strictly positive for $\triangle \hat{\theta} \neq 0$ unless $f^{\prime}(n \hat{\theta})-\alpha=0$. Thus, any equilibrium must have $f^{\prime}(n \hat{\theta})-\alpha=0$. Therefore there exists a symmetric equilibrium level of contributions $\theta^{*}$ such that $f^{\prime}\left(n \theta^{*}\right)-\alpha=0$

Finally, we need to check that no caring consumer would defect to firms catering for neutral consumers and vice versa. The latter part is obvious: neutral consumers do not value the public good, and so will be strictly worse off paying a higher price for the private good. The former requires that:

$$
b-\alpha \theta^{*}-c+f\left(\theta^{*} n\right) \geq b-c+f\left(\theta^{*}(n-1)\right) .
$$

Thus, we require that

$$
f\left(\theta^{*} n\right)-f\left(\theta^{*}(n-1)\right)-\alpha \theta^{*} \geq 0 .
$$

As $f^{\prime}\left(\theta^{*} n\right)=\alpha$, substituting and rearranging terms we get

$$
\frac{f\left(\theta^{*} n\right)-f\left(\theta^{*}(n-1)\right)}{\theta^{*}} \geq f^{\prime}\left(\theta^{*} n\right) .
$$

As $f($.$) is strictly concave, this holds (with strict inequality). QED$

Proof of Observation 5: Step 3 of the proof of Proposition 1 now needs to be modified because due to the warm-glow term now it is possible that two caring consumers are offered two packages $\left(p_{c}^{1}, \theta_{c}^{1}\right)$ and $\left(p_{c}^{2}, \theta_{c}^{2}\right)$ where $p_{c}^{1} \neq p_{c}^{2}$ and/or $\theta_{c}^{1} \neq \theta_{c}^{2}$ and they are indifferent :

$b-\left(c+\alpha \theta_{c}^{1}\right)+f\left(\theta_{c}^{1}+\theta_{c}^{2}+\hat{G}\right)+v\left(\theta_{c}^{1}\right)=b-\left(c+\alpha \theta_{c}^{2}\right)+f\left(\theta_{c}^{2}+\theta_{c}^{1}+\hat{G}\right)+v\left(\theta_{c}^{2}\right)$

or, $v\left(\theta_{c}^{1}\right)-v\left(\theta_{c}^{2}\right)=\alpha\left(\theta_{c}^{1}-\theta_{c}^{2}\right)$. Without loss of generality, let $\theta_{c}^{1}>\theta_{c}^{2}$. We show that consumer 1 is strictly better off with a package $\left(c+\alpha \frac{\theta_{c}^{1}+\theta_{c}^{2}}{2}, \frac{\theta_{c}^{1}+\theta_{c}^{2}}{2}\right)$ and as a result in equilibrium the same package will be offered to all consumers. We need to show $v\left(\theta_{c}^{1}\right)-\alpha \theta_{c}^{1}<v\left(\frac{\theta_{c}^{1}+\theta_{c}^{2}}{2}\right)-\alpha \frac{\theta_{c}^{1}+\theta_{c}^{2}}{2}$, or $v\left(\theta_{c}^{1}\right)-$ 
$v\left(\frac{\theta_{c}^{1}+\theta_{c}^{2}}{2}\right)<\alpha \frac{\theta_{c}^{1}-\theta_{c}^{2}}{2}$. But as $v\left(\theta_{c}^{1}\right)-v\left(\theta_{c}^{2}\right)=\alpha\left(\theta_{c}^{1}-\theta_{c}^{2}\right), \alpha \frac{\theta_{c}^{1}-\theta_{c}^{2}}{2}=\frac{v\left(\theta_{c}^{1}\right)-v\left(\theta_{c}^{2}\right)}{2}$ and by the concavity of $v(),. \frac{v\left(\theta_{c}^{1}\right)-v\left(\theta_{c}^{2}\right)}{2}>v\left(\theta_{c}^{1}\right)-v\left(\frac{\theta_{c}^{1}+\theta_{c}^{2}}{2}\right)$ as that is equivalent to $v\left(\frac{\theta_{c}^{1}+\theta_{c}^{2}}{2}\right)>\frac{1}{2} v\left(\theta_{c}^{1}\right)+\frac{1}{2} v\left(\theta_{c}^{2}\right)$. The rest of proof follows straightforwardly by adapting the proof of Proposition 1 to this case (in particular, noting that in equilibrium $f^{\prime}\left(\theta_{c}^{*} n\right)+v^{\prime}\left(\theta_{c}^{*}\right)=\alpha$ and that adding the warmglow effect reinforces the self-selection constraint of caring consumers). QED

Proof of Proposition 2: First, given the strategies of the firms and the consumers, the incentive-compatibility constraint $p_{c} \geq c+\phi(q, \beta) \alpha \theta_{c}$ must hold with strict equality. If $p_{c}$ is strictly higher than $c+\phi(q, \beta) \alpha \theta_{c}$ then another firm can enter, paying the same up front cost $F$, and offer a slightly lower price and attract all the caring consumers. If If $p_{c}<c+\phi(q, \beta) \alpha \theta_{c}$ then consumers will rationally expect the firm not to be able to supply the promised level of the public good and will be better off by going to firms offering the neutral version of the product.

Second, given that $p_{c}=c+\phi(q, \beta) \alpha \theta_{c}$ in equilibrium, we can use the same argument as in the proof of Proposition 1 to prove that all caring consumers will be offered the same package $\left(\hat{p}_{c}, \hat{\theta}_{c}\right)$.

Third, suppose $f^{\prime}\left(n \hat{\theta}_{c}\right) \neq \phi(q, \beta) \alpha$ in equilibrium. We can use the same arguments as in Proposition 1 to show that a new firm can enter and offer a new package with a different $(p, \theta)$ combination and make positive profits. There is only a slight modification to this argument: any new $(p, \theta)$ offer must satisfy the incentive constraint for the new offer to be credible, and therefore $\triangle p$ must equal $\phi(q, \beta) \alpha \triangle \hat{\theta}$.It is as if that $\phi(q, \beta) \alpha>\alpha$ is the new marginal cost of providing the public good, instead of $\alpha$.

For the remainder of the proof we can apply Proposition 1. As $\phi(q, \beta)>1$ and $f($.$) is concave, it follows directly that the level of the public good that$ will be provided in equilibrium will be less than in the perfect monitoring case. QED

Proof of Proposition 5: Let $G_{t}=\arg \max \left(f(G)-\frac{\alpha}{t} G\right)$. Then social surplus under government provision is $S_{N}=n f\left(G_{N}\right)-\alpha G_{N}$ and that under CSR is $S_{1}=n f\left(G_{1}\right)-\alpha G_{1}$. Because $f(G)$ is concave, $\left(G_{N}-G_{1}\right) f^{\prime}\left(G_{N}\right) \leq$ $f\left(G_{N}\right)-f\left(G_{1}\right) \leq\left(G_{N}-G_{1}\right) f^{\prime}\left(G_{1}\right)$. Using the relevant first-order conditions, we get $\left(\frac{n}{N}-1\right) \leq \frac{S_{N}-S_{1}}{\left(G_{N}-G_{1}\right) \alpha} \leq(n-1)$. Also, by the mean-value theorem, there exists $t=t(N) \in(1, N)$ such that $f\left(G_{N}\right)-f\left(G_{1}\right)=\left(G_{N}-G_{1}\right) f^{\prime}\left(G_{t}\right)$. 
By the concavity of $f(G), t(N)$ is increasing in $N$. The larger is $n$, the closer is $G_{N}$ to $G_{n}$ (the first-best level). Since we focus on $\pi \geq \frac{1}{2}$, the lowest permissible value of $n$ is $\frac{N}{2}$. In this case, the lower bound of $\frac{S_{N}-S_{1}}{\left(G_{N}-G_{1}\right) \alpha}$ is $-\frac{1}{2}$ while the upper bound is increasing with $N$. As $t(N)$ is increasing, it moves closer to $N$ relative to 1 as $N$ increases and this completes the proof that there is $\underline{N}$ such that for $N \geq \underline{N}$ government provision dominates CSR. Also, $\underline{N}>1$ since for $N=1$ government provision, CSR, and the first-best all coincide.QED 